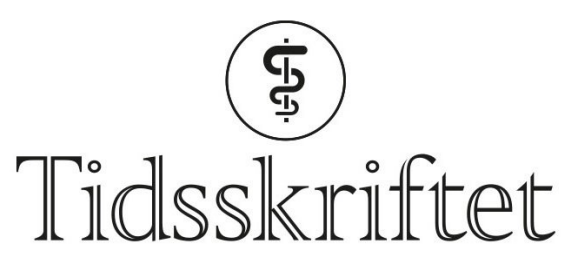

DEN NORSKE LEGEFORENING

\title{
Dansens gud
}

ESSAY

\section{ALV A. DAHL}

E-post:alvandreas@msn.com

Alv A. Dahl er spesialist i psykiatri ved Ressursklinikken, Lillestrøm.

Forfatteren har fylt ut ICMJE-skjemaet og oppgir ingen interessekonflikter.

Den russiske danseren Vaslav Nijinsky (1889-1950) hadde en traumatisk oppvekst før han 20 år gammel la verden for sine føtter med det russiske ballettkompaniet. 30 år gammel ble han psykotisk. Han ble behandlet med ulike metoder av tidens ledende psykiatere, uten vesentlig bedring. I en dagbok beskrev han sine psykotiske opplevelser. Denne fremstillingen bygger på lesing av dagboken, samtidig sekundærlitteratur og senere vurderinger av biografer og psykiatere. 


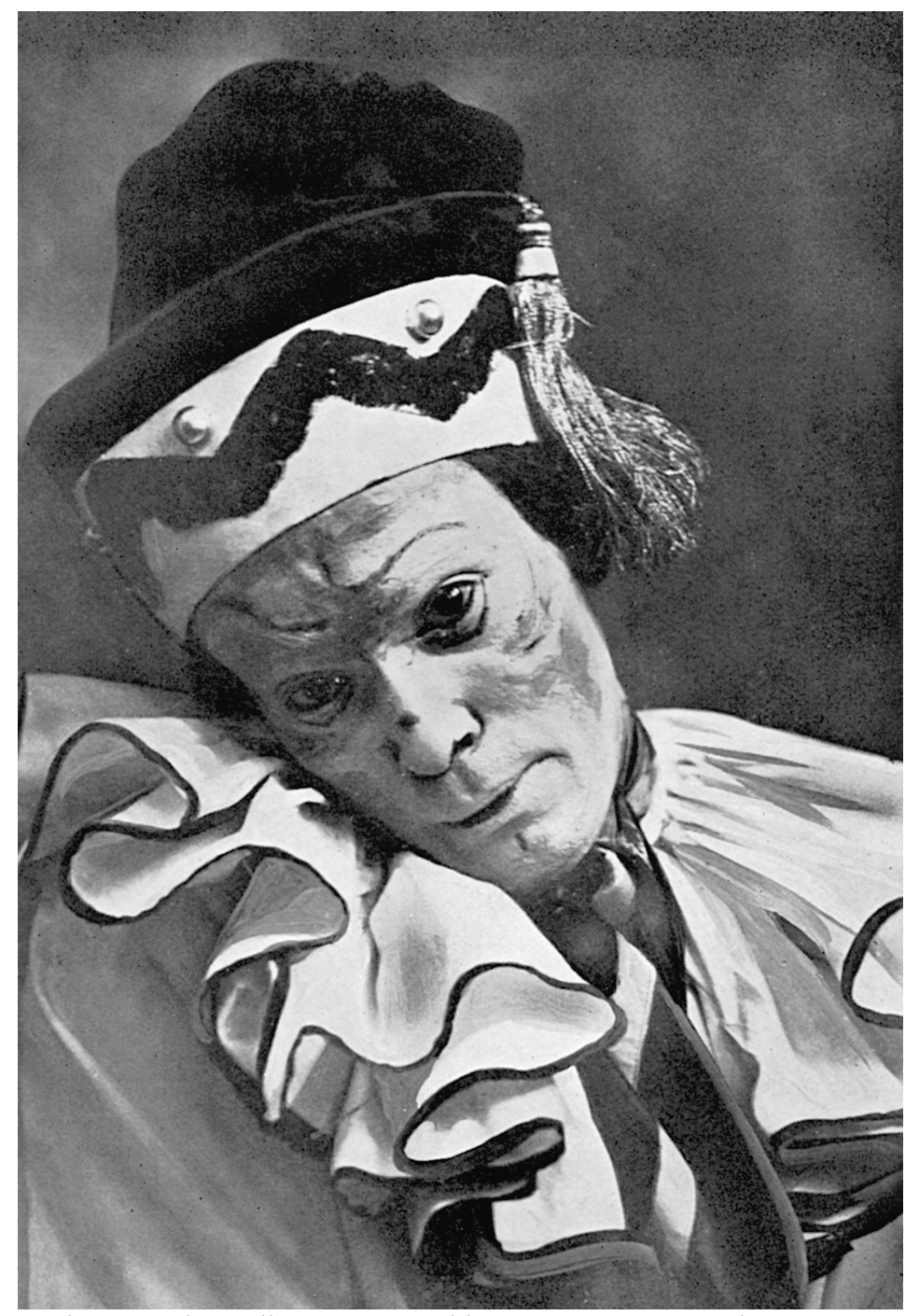

Vaslav Nijinsky i rollen som Petrushka i oppsetningen med samme navn. Premieren var 13.juni 1911 på Théâtre du Châtelet i Paris. Foto: Shutterstock editorial / NTB Scanpix

Vaslav Nijinsky ble født i Russland i 1889. Kort etter fødselen fikk hans eldre bror en alvorlig traumatisk hjerneskade og tilbragte mye av livet på institusjon. Da Nijinsky var fem år, forlot faren familien for en yngre kvinne, og moren tok hånd om barna.

Ti år gammel ble Nijinsky innskrevet ved den keiserlige russiske ballettskolen i St. Petersburg og regnet som vidunderbarn. Gjennom årene der ble han vedvarende mobbet fordi han ikke var adelig, han snakket polsk-russisk, var likegyldig med uniformen - og var flinkere enn alle andre. Da han var tolv år gammel, såpet medelevene gulvet slik at han falt og pådro seg en alvorlig bukskade med leverruptur og svær blødning. Sannsynligvis fikk han også en hodeskade i form av et vannskilleinfarkt, og lå i koma i fem døgn. I forbindelse med 1905-revolusjonen tok hans personlige lærer livet sitt. Da Nijinsky ble uteksaminert i 1907, var han allerede en lokal berømthet (1-3).

Ballettelevene ble dyrket og sponset av adelsmenn, og Nijinsky hadde sitt første seksuelle forhold til en av dem. I 1908 møtte han Sergej Djagilev (1872-1929), som var impresario og leder for Ballets Russes, et kompani som hadde gjort sensasjon ute i Europa. Nijinsky ble ballettens store trekkplaster i årene som fulgte. Igor Stravinskij (1882-1971) og Maurice Ravel (1875-1937) komponerte balletter for den, og Pablo Picasso (1881-1973) malte kulisser. For Nijinsky var Djagilev både sjef og seksualpartner, og gjennom han møtte Nijinsky den europeiske kultureliten. Han kunne bare dans, hadde minimalt med skolegang, snakket bare russisk og var svært innadvendt som person. Innen Djagilevs omgangskrets falt han igjennom på alt unntatt dansen, og ambivalensen dem imellom økte. Nijinsky prøvde å frigjøre seg, mens Djagilev forgjeves prøvde å finne en danser som kunne erstatte Nijinsky. I 1913 møtte Nijinsky den jevnaldrende, ungarske sosietetskvinnen Romola de Pulszky 
(1891-1978), datter av den berømte skuespillerinnen Emilia Márkus (1860-1949). De Pulszky var betatt av Nijinskys stjernestatus, og han ville bort fra Djagilev, så de giftet seg raskt. Nijinsky fikk dermed sparken, og 1914 startet med at han var uten inntekt og kona var gravid. Paret reiste til hennes familie i Budapest, og straks etter startet første verdenskrig. Fordi Nijinsky var russer, satt han i husarrest i 18 måneder. I oktober 1914 fikk han den første alvorlige psykiske krisen preget av depresjon, irritabilitet, søvnløshet og brystsmerter. Han fikk motediagnosen nevrasteni og ble bedt om å ta det med ro og unngå ansvar. Følgen var at han la seg til i sengen, og det tok nesten et år før han var i form igjen (2).

\section{Psykosens start og utvikling}

Takket være diplomati på høyeste plan fikk Nijinsky-familien forlate Ungarn mot at han igjen sluttet seg til Ballets Russes. Nå fikk han ansvar for en stor turné til USA og Canada. Kunstnerisk var den strålende, men økonomisk en katastrofe. Mens krigen fortsatte, besøkte ensemblet det nøytrale Spania. Det var første gang Nijinsky turnerte sammen med både kona og Djagilev, og sjalusi- og pengekonflikter var daglig kost mellom de tre. Til slutt nektet Nijinsky å danse. Han prøvde å rømme og ble brakt tilbake på scenen av politiet $\mathrm{i}$ Barcelona i juni 1917. Det ble Nijinskys siste forestilling i Europa, og han dro med familien til en opptreden i Buenos Aires. Der møtte han igjen sin gamle klassekamerat Anatole Bourman (1888-1962), som ble slått av Nijinskys psykiske forandring med forfølgelsesforestillinger (1). Nijinsky viste Bourman nye originale dansesekvenser, men Bourman fant dem fysisk umulige og mente at Nijinsky var gal.

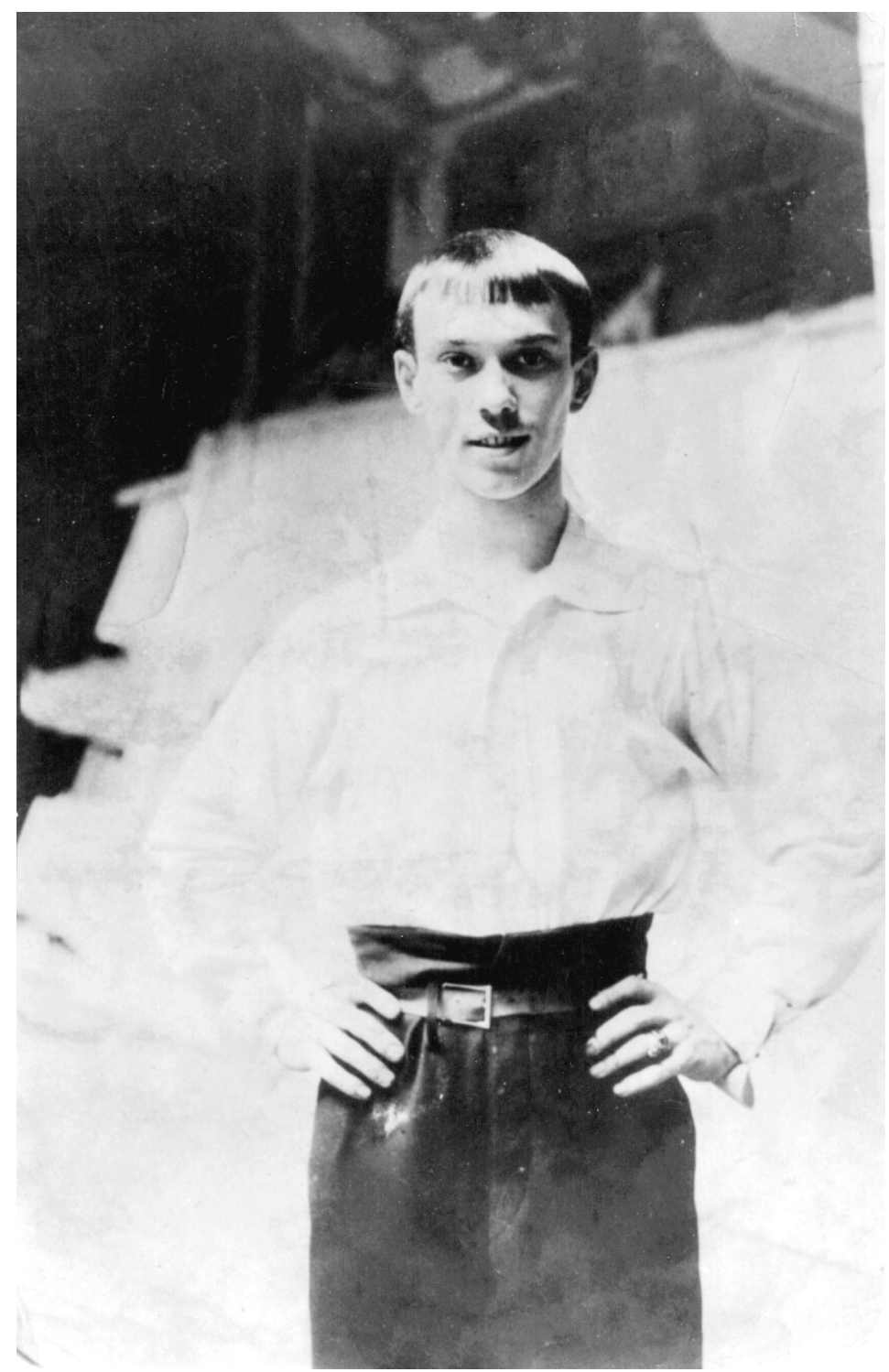

18 år gamle Nijinsky fotografert på Krasnoje Selo ved St. Petersburg, hvor han spilte på et lite teater for den russiske eliten. Foto: Musikkavdelingen ved Library of Congress, USA 
På nytt fikk Nijinsky sparken, krigen i Europa fortsatte og i tillegg hadde 1917-revolusjonen utløst borgerkrig i hjemlandet. Familien slo seg derfor ned i St. Moritz i Sveits. Nijinsky kunne ikke danse lenger, og var psykisk ubalansert. Hans lege i St. Moritz, Hans Frenkel, prøvde å behandle ham med frie assosiasjoner og kloralhydrat, men Nijinsky ble bare verre. Det er uklart om han visste at Frenkel samtidig hadde et forhold til kona hans. Frenkel ba sin læremester fra Zürich, Eugen Bleuler (1857-1939), om å vurdere Nijinsky. Bleuler hadde i 1911 formulert sitt dynamiske schizofreni-begrep i opposisjon til Kraepelins statiske dementia praecox-begrep (4). Bleuler møtte Nijinsky i mars 1919 på Bürghölzli-hospitalet og konkluderte slik: «Intelligensen har åpenbart vært veldig god tidligere, men nå er han en forvirret schizofren med mild manisk eksitasjon.» (2). Bleuler anbefalte ikke innleggelse, men etter en voldsepisode to dager senere, ble Nijinsky innlagt.

Han kunne bare dans, hadde minimalt med skolegang, snakket bare russisk og var svært innadvendt som person

Nijinskys dagbøker fra januar til mars 1919 styrker schizofrenidiagnosen. Her omtaler han hendelser fra livet sitt, særlig offerrollen med Djagilev som overgriper, og strømmen av følelser og tanker slik de meldte seg dag for dag. Setningene er korte, enkle, gjentakende og ofte selvmotsigende. Tankeforstyrrelsene blomstrer i teksten med klangassosiasjoner, manglende logisk sammenheng, gjentakelser og meningsløse fraser. I tillegg kommer grove seksuelle ord og uttrykk.

Kona hadde hele tiden drømt om at Nijinsky skulle bli frisk og rik gjennom dansen. Årene gikk uten bedring, og behandling og pleie kostet dyrt. Hun tenkte derfor at de kunne tjene penger på å gi ut dagbøkene. Hun ba den kjente østerrikske psykiateren Alfred Adler (1870-1937) om å skrive forord. Adler besøkte Nijinsky på sykehuset i 1934 og skrev et forord ut fra sin teori om mindreverdighetsfølelsens sentrale betydning som årsaksfaktor. Det likte ikke kona, derfor skrev hun forordet selv og sensurerte dagbøkene for alt anstøtelig (5). Etter hennes død i 1978 ble de originale dagbøkene funnet og utgitt på engelsk (6). Adlers forord sammen med en omfattende diskusjon av det ble trykt i Archives of General Psychiatry i 1981 (7). Mange mener at dagbøkene er viktig lesing for den som vil forstå den indre verdenen som pasienter med schizofreni lever i (8).

\section{Psykosens videre forløp}

I mars 1919 ble Nijinsky innlagt på Bellevue-sanatoriet i Kreuzlingen, som var ledet av den sveitsiske psykiateren Ludwig Binswanger (1881-1966). Binswanger var utdannet sammen med Bleuler og Carl Gustav Jung (1875-1961), og var en livslang venn av Sigmund Freud (1856-1939). Han var eksistensfilosofisk skolert og utviklet en eksistensiell psykoterapi demonstrert ved behandlingen av en kvinne med spiseforstyrrelse, Ellen West (1888-1921) (9). Bellevue var en familiebedrift, og Nijinskys psykiater Kurt Binswanger (1887-1981) var Ludwigs fetter. Han var overlege på en avdeling som nærmest var et terapeutisk samfunn uten bruk av medikamenter eller tvangsmidler og med terapi ut fra psykoanalytiske prinsipper. 


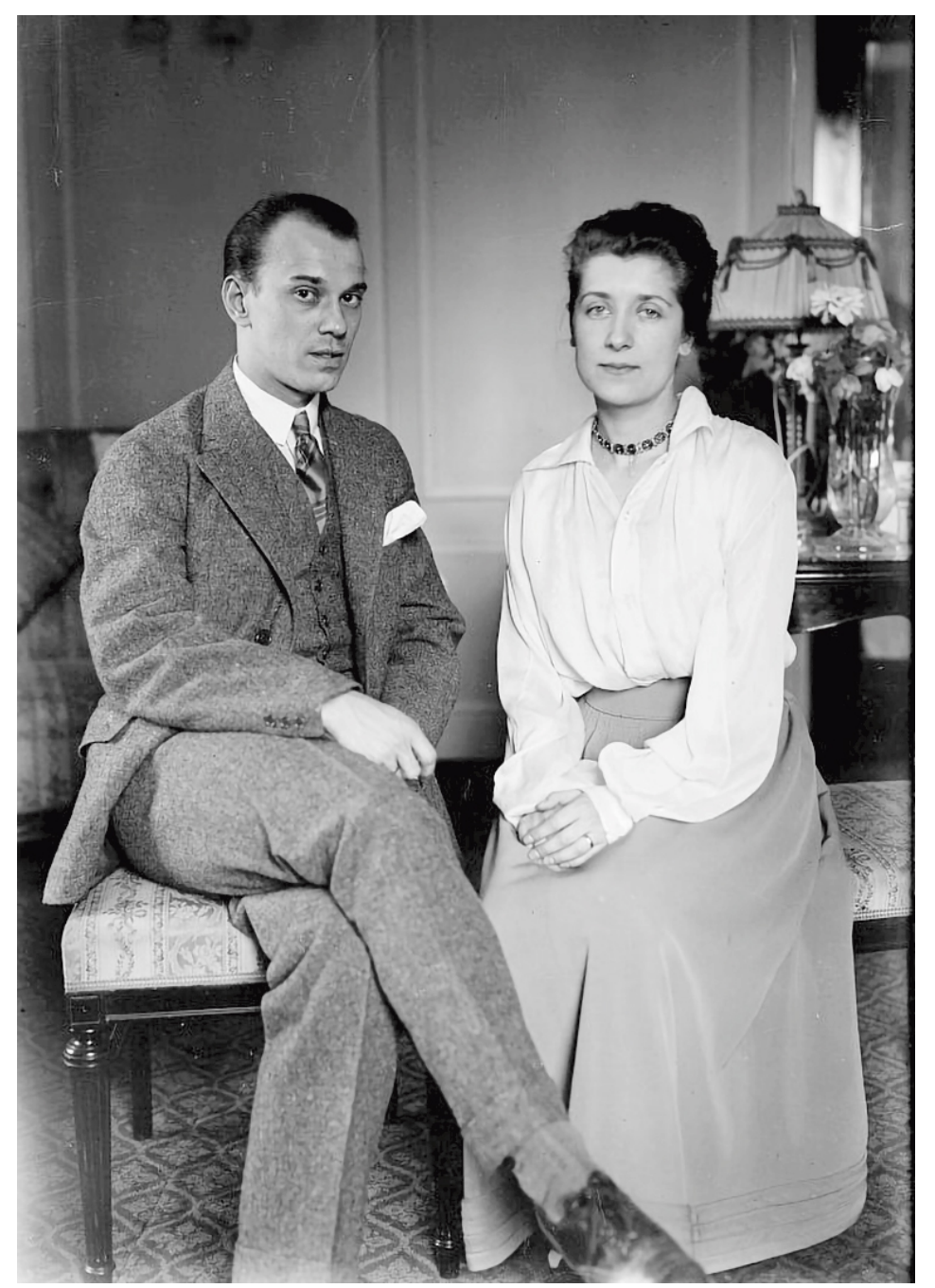

Nijinsky og kona Romola de Pulszky i 1916. Foto: Flickr Commons project/Wikimedia commons

De første månedene der var Nijinsky gjentatte ganger voldelig, snakket ikke, var i ubevegelige stillinger, blottet seg, hørte stemmer og hadde vrangforestillinger. Han fikk diagnosen psykogen katatoni. Kona la seg stadig opp i behandlingen, og etter en tid tok hun han hjem for å pleie han selv. Da han ble gjeninnlagt fire måneder senere, var han klart forverret, med veksling mellom stillstand og frenetiske bevegelser, plutselig vold, hallusinasjoner, vrangforestillinger og dårlig hygiene.

I mars 1920 ble Nijinsky overført til sykehuset Steinhof i Wien. Det var ledet av Julius Wagner-Jauregg (1857-1940), som sju år senere skulle få nobelprisen i fysiologi eller medisin for malariabehandlingen av paralysis generalis. Journalene fra Steinhof ble makulert, men det er ingen kilder som hevdet at sykdomsbildet eller behandlingen endret seg. Etter mange år møtte Nijinsky sin mor og yngre søster, som også var en berømt ballerina, igjen . Men hverken møtet eller det at han fikk en ny datter, gjorde tilsynelatende inntrykk. Nijinsky tilbragte resten av 1920-årene på ulike psykiatriske sykehus, og i 1930 kom han tilbake til Bellevue. Mye av denne tiden var kona i USA og forsøkte å skape sin egen karriere, og hun viste åpent sin lesbiske legning. Nijinskys symptombilde var fortsatt eksitert og passiv katatoni, vold, stereotyp atferd, usammenhengende språk og periodisk mutisme (2). Slik gikk fem år på Bellevue inntil kona kom tilbake til Sveits.

Kona hadde hele tiden drømt om at Nijinsky skulle bli frisk og rik gjennom dansen

Hun hadde hørt lovord om en ny biologisk behandling introdusert av den østerrikske psykiateren Manfred Sakel (1900-57) i 1928. Ved å gi pasientene insulin fremkalte han en grad av hypoglykemi som skulle drepe syke og svake nevroner. Sakel hevdet at pasienter med psykoser og stoffmisbruk ble bedre etterpå (10). Insulinkomabehandlingen bredte seg i psykiatrien. Risikoen for langvarige kramper og hjerneskade var betydelig, og pasientene måtte derfor overvåkes nøye, slik at komaene var passe dype og lange. Mange mente at den 
gunstige effekten skyldtes det tette forholdet mellom pasienter og personalet på insulinkomastuene (11). Fra 1938 skal Nijinsky ha fått til sammen 48 insulinkomabehandlinger på Bellevue før Binswanger sa stopp. Nijinsky ble flyttet til et annet sykehus der han fikk ytterligere 180 behandlinger. Han skal ha vist forbigående bedring før han gled tilbake i vekslende katatoni, mutisme og vold.

\section{Sluttstadiet}

Familien var i Sveits da den andre verdenskrigen brøt ut i 1939, men bestemte seg for å dra til hennes familie i Budapest. Nazistene invaderte Ungarn, og på grunn av schizofrenien var Nijinsky truet av deres utryddelsesprogram. Han ble flyttet til et fjerntliggende lite sykehus, og da programmet var på sitt verste i 1945, var han og kona gjemt i jordhuler. Da den røde armé erobret Ungarn kort etter, møtte Nijinsky igjen barndommens russere. Dette fremkalte en markant bedring, og for første gang på 26 år snakket han på vanlig måte og danset sammen med soldatene. Igjen var bedringen kortvarig, men senere var det slutt på vold og eksitasjon. I 1948 flyttet paret til London. Nijinsky døde av uremi som følge av kronisk nefritt i 1950.

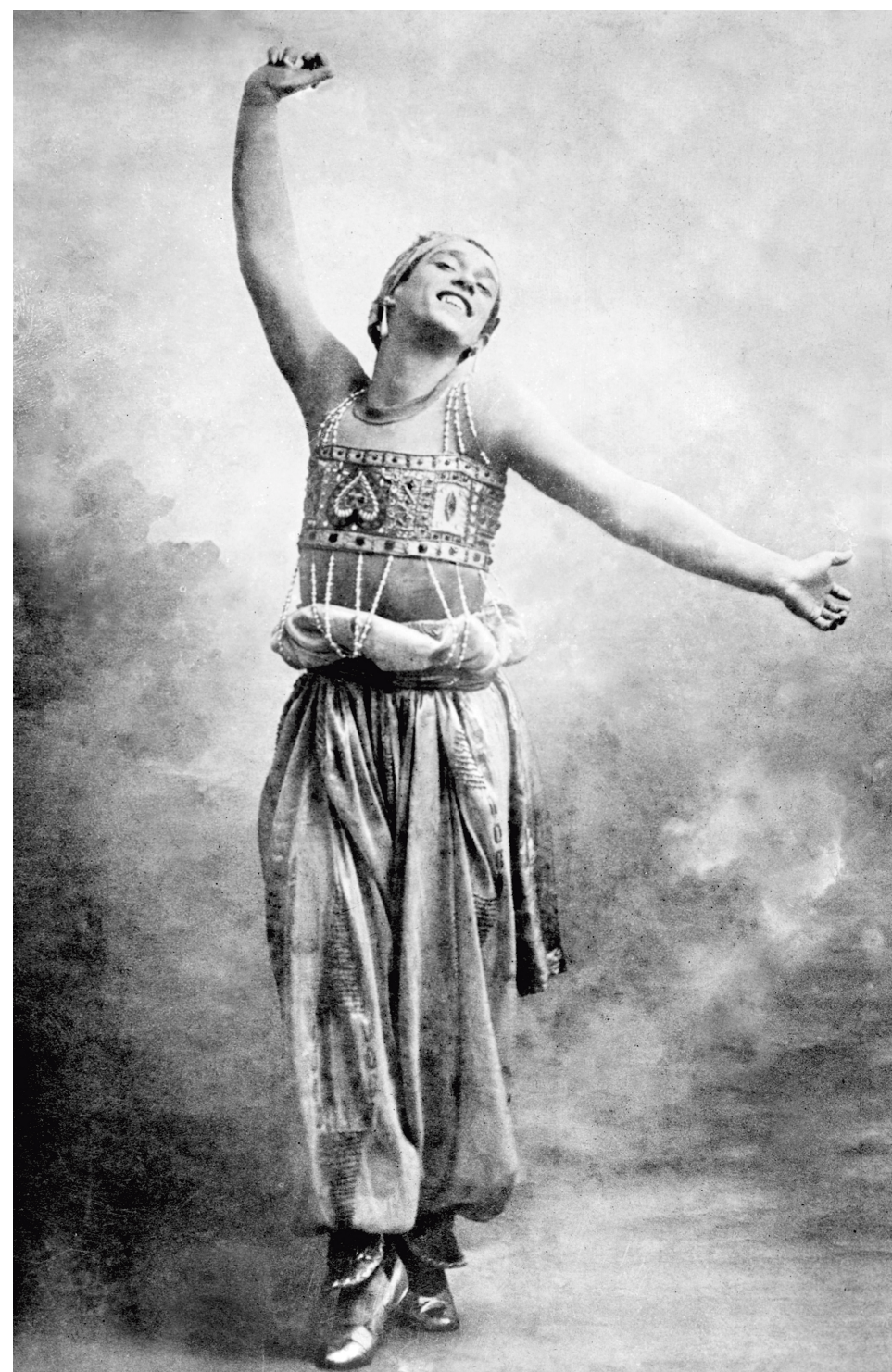

I ballettforestillingen Scheherazade fra 1910 spilte Nijinsky gullslaven, som var malt med og kledd $i$ gull. Det erotiske stykket var kontroversielt ved å vare en av de første gangene en orgie ble simulert på scenen. Foto: Alamy stock photo

\section{Noen refleksjoner}

Ifølge dagens teori har schizofreni multiple årsaker (12). Hos Nijinsky finner vi ingen 
dokumentert familiær opphopning eller «myke» nevrologiske tegn (neurological soft signs), men han opplevde en rekke tap, langvarig mobbing, var komatøs etter en skade og ble seksuelt traumatisert. Han var androgyn og danset både manns- og kvinneroller like suverent. Det er ikke vanskelig å se for seg at identitetsusikkerhet kan ha gjort Nijinsky sårbar.

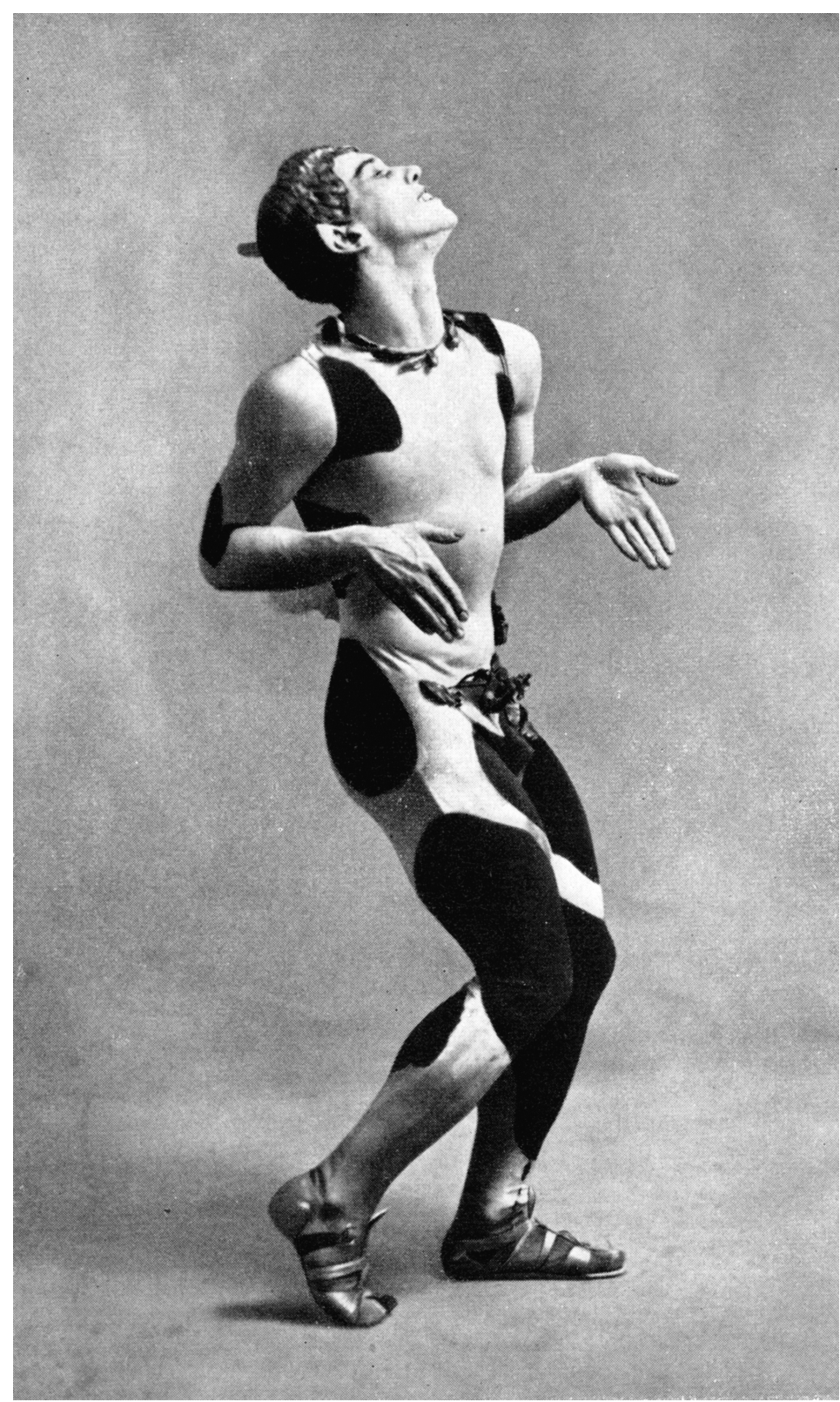

Nijinsky koreograferte og danset hovedrollen i Faunens ettermiddag $i$ 1912, til musikk av Claude Debussy og dekor av Leo Bakst. Foto: Alamy stock photo

En annen synsvinkel er at han kan ha hatt en autismespekterforstyrrelse, sett ut ifra diagnosekriteriene i DSM-5 (13): Han snakket lite, manglet sosial intelligens, var passiv i relasjoner og hans eneste altoppslukende interesse var dans og ballett.

Katatoni kjennetegnes av $ø$ kt eller redusert psykomotorisk aktivitet, et sentralt symptom hos Nijinsky. Han hadde i utgangspunktet hatt en suveren motorikk og hadde bergtatt publikum gjennom det han greide å uttrykke følelsesmessig med kroppen.

Det er ikke vanskelig å se for seg at identitetsusikkerhet kan ha gjort Nijinsky sårbar

Sammenhengen mellom autismespekterforstyrrelser og katatoni er veldokumentert (14). Katatoni var i utgangspunktet en selvstendig psykisk lidelse, men Kraepelin gjorde den til en undergruppe av schizofreniene. Slik er det fortsatt i ICD-10 (15), mens DSM-5 igjen har gjort katatoni til en selvstendig lidelse (13). Det henger blant annet sammen med den gode effekten av elektrostimulering og benzodiazepiner, som man ellers ikke finner ved 
schizofreni. Nijinskys utbrente sluttstadium kan tyde på at Bleulers schizofrenidiagnose var riktig, selv om den amerikanske psykiateren Peter Ostwald (1928-96) i sin detaljerte bok om Nijinskys psykiske lidelser ender opp med diagnosene schizoaffektiv psykose og narsissistisk personlighetsforstyrrelse (2).

Nijinskys behandlingshistorie viser hvor resistent schizofreni kan være. Tidlig i forløpet fikk han beroligende legemidler og miljøterapi, senere ble han godt passet på av erfarne pleiere og til slutt fikk han omfattende insulinkomabehandling. Ingenting hjalp. Han opplevde to verdenskriger og den russiske revolusjon uten at slike ytre forhold påvirket sykdomsforløpet. Som man iblant ser ved schizofreni, kan mer normal atferd vise seg ved sterke inntrykk, som møtet med de russiske soldatene i 1945.

Fra midten av 1400-tallet og frem til i dag har vi pasienters egne beskrivelser av det å være psykotisk. Nijinskys dagbøker er en klassiker i denne litteraturen (16). Som psykiatriske fagfolk kan vi takke han for dette instruktive bidraget til vår forståelse av hvordan det er å oppleve utviklingen av schizofreni.

\section{LITTERATUR:}

1. Bourman A. The tragedy of Nijinsky. Binsted: The Noverre Press, 2010.

2. Ostwald P. Nijinsky: A leap into madness. London: Robson Books, 1999.

3. Moore L. Nijinsky. A life. London: Profile Books, 2013.

4. Bleuler E. Dementia Praecox or the group of schizophrenias. New York, NY: International Universities Press, 1911/1950.

5. Nijinsky R. The diary of Vaslav Nijinsky. New York, NY: Simon \& Schuster, 1936.

6. Acocella J. The diary of Vaslav Nijinsky. Unexpurgated edition. Urbana, IL: Unversity of Illinois Press, 1999.

7. Ansbacher HL. Discussion of Alfred Alder's preface to The Diary of Vaslav Nijinsky. Arch Gen Psychiatry 1981; 38: 836-41. [PubMed][CrossRef]

8. Fernandez-Egea E. One hundred years ago: Nijinsky and the origins of schizophrenia. Brain 2019;142: 220-6. [PubMed][CrossRef]

9. Binswanger L. Schizophrenie. Pfullingen: Neske Verlag, 1957.

10. Shorter E. Sakel versus Meduna: different strokes, different styles of scientific discovery. J ECT 20o9; 25: 12-4. [PubMed][CrossRef]

11. Doroshow DB. Performing a cure for schizophrenia: insulin coma therapy on the wards. J Hist Med Allied Sci 2007; 62: 213-43. [PubMed][CrossRef]

12. Howes OD, Murray RM. Schizophrenia: an integrated sociodevelopmental-cognitive model. Lancet 2014;383: 1677-87. [PubMed][CrossRef]

13. American Psychiatric Association. Diagnostic and statistical manual if mental disorders. Fifth edition. Washington, DC: American Psychiatric Publishing, 2013.

14. Peralta V, Cuesta MJ. Motor abnormalities: From neurodevelopmental to neurodegenerative through "functional" (neuro)psychiatric disorders. Schizophr Bull 2017; 43: 956-71.

[PubMed][CrossRef]

15. Verdens helseorganisasjon. ICD-10. Psykiske lidelser og atferdsforstyrrelser. Kliniske retningslinjer og diagnostiske retningslinjer. Oslo: Gyldendal Akademisk, 2000.

16. Peterson D. (red). A mad people's history of madness. Pittsburgh, PA: University of Pittsburgh, 1982.

Publisert: 9. januar 2020. Tidsskr Nor Legeforen. DOI: 10.4045/tidsskr.19.0669

(C) Tidsskrift for Den norske legeforening 2020. Lastet ned fra tidsskriftet.no 